\title{
How do Coaches' Attitudes Change When Exposed to a Sport Psychology Workshop?
}

\author{
Rebecca A. Zakrajsek \\ Indiana State University \\ Sam Zizzi \\ West Virginia University, Sam.Zizzi@mail.wvu.edu
}

Follow this and additional works at: https://researchrepository.wvu.edu/faculty_publications

\section{Digital Commons Citation}

Zakrajsek, Rebecca A. and Zizzi, Sam, "How do Coaches' Attitudes Change When Exposed to a Sport Psychology Workshop?" (2008). Faculty \& Staff Scholarship. 2921.

https://researchrepository.wvu.edu/faculty_publications/2921

This Article is brought to you for free and open access by The Research Repository @ WVU. It has been accepted for inclusion in Faculty \& Staff Scholarship by an authorized administrator of The Research Repository @ WVU. For more information, please contact ian.harmon@mail.wvu.edu. 


\title{
Journal of Coaching Education
}

\section{How do Coaches’ Attitudes Change When Exposed to a Sport Psychology Workshop?}

Rebecca A. Zakrajsek

Indiana State University, Terre Haute

Sam J. Zizzi

West Virginia University, Morgantown

\begin{abstract}
This study examined: (1) coaches' attitudes and readiness to use sport psychology (SP) services immediately following a SP workshop; and (2) the impact of an educational intervention on coaches' attitudes and usage patterns during a one-month follow-up. Ninety swim coaches participated in the SP workshop and a total of 53 swim coaches completed the one-month follow-up. The majority of the sample coached at the high school or age group level. Data provided some evidence for the impact of a SP workshop on stage of change, with approximately $13 \%$ of coaches moving from precontemplation to contemplation. Two-way mixed ANOVAs did not reveal significant interactions (group x time) and main effects for time found that coaches' personal openness, behavioral control, self-efficacy, and intentions increased while perceived barriers decreased immediately post-workshop. Furthermore, changes in coaches' perceived barriers, behavioral control, and self-efficacy were maintained at the one-month follow-up while personal openness and intentions returned close to baseline. Lastly, no differences were found between the stage-matched and control group with regard to behavioral SP usage patterns (e.g., contacting a SP consultant, seeking out more information about SP). However, approximately $40 \%$ of coaches accessed the website during the four-week follow-up. The appropriateness of the transtheoretical model of behavior change applied to SP service use with coaches will be discussed.
\end{abstract}

\section{Introduction}

The literature has recognized the need to develop coach education programs that balance technical and tactical knowledge with other areas such as sport psychology (SP; Cale \& Crisfield, 1994; Cassidy, Potrac, \& McKenzie, 2006). In addition, the National Association for Sport and Physical Education (NASPE) has published the National Standards for Sport Coaches (NSSC, 2006) in order to standardize the skills and knowledge that can be expected of coaches at various levels of competition. Principles within SP are weaved through the domains and standards, showing that the mental and physical aspects of sport are integrated rather than separate components of training. Designing curriculums that meet the NSSC is an important step within coaching education and may help to increase familiarity and use of SP. Researchers have reported that only about $20 \%$ of coaches sampled use some form of SP services (Zakrajsek \& Zizzi, 2007); therefore, the majority have yet to make the shift between interest and willingness to actual implementation of SP into training. Lack of funding and time constraints have been consistently reported as some of the most common reasons why coaches and university athletic $\begin{array}{lll}\text { Volume 1, Is 1,sue } & \text { March } 2008 & \text { Page } 66\end{array}$

A publication from the National Association for Sport and Physical Education (NASPE), an association in the American Alliance for Health, Physical Education, Recreation and Dance (AAHPERD) 1900 Association Drive • Reston, Virginia • 20191 • www.NASPEinfo.org • 703.476.3410 (C)2008 by NASPE. All Rights Reserved. 


\section{Journal of Coaching Education}

departments do not utilize mental skills training or SP services (Gould, Medberry, Damarjian, \& Lauer, 1999; Haslam, 2004; Kremer \& Marchant, 2002; Pain \& Harwood, 2004; Voight \& Callaghan, 2001). Accessibility may be another factor, in which 34\% of elite level coaches sampled reported not knowing how they would go about identifying and accessing a SP consultant (Scully \& Hume, 1995). The limited training and familiarity with SP may lead some coaches to be hesitant to implement SP into training and some coaches may form negative attitudes or misperceptions toward the field.

Negative connotations associated with the discipline of SP continue to be reported by coaches as a barrier to SP service use (Kremer \& Merchant, 2002; Pain \& Harwood, 2004). Some coaches still hold the misconception, for example, that SP is for problem athletes only. They are also aware that athletes could be ridiculed for seeing a SP consultant due to the term "psychology" being within the title. Other coaches have expressed a fear that SP would make their athletes think too much about their game, which might reduce performance (Haslam, 2004). Other expectations about the process of SP consultations may influence willingness to seek service use (Martin et al. 2001). For instance, coaches may expect the SP consultant to openly discuss an athlete's problems (Zakrajsek \& Zizzi, 2007). Within the athletic environment, coaches often talk among themselves about their athletes (Speed, Andersen, \& Simons, 2005) and the perceived lack of feedback and not knowing what is happening may be viewed as limiting the value of SP (Pain \& Harwood). From the literature, it appears that coaches consider several factors when weighing the decision to use SP services. Some coaches may be aware of the benefits of using SP services but the perceived barriers (e.g., stigma, access, time, money, expectations, and confidence in SP) continue to inhibit readiness to integrate SP into training. For example, Zakrajsek and Zizzi (2007) surveyed 374 track and swimming coaches and found that confidence in SP consultation, stigma tolerance, and expectations predicted coaches' intentions to use SP services and accounted for 38\% of the total variance. Thus, in order to increase service use, professionals should address coaches' attitudes, beliefs, and motivational readiness to use SP services within a theoretical framework.

Within the transtheoretical model (TTM; Prochaska \& DiClemente, 1983), behavior change is viewed as a process with predictable stages: precontemplation (not thinking about change); contemplation (thinking about changing in the next few months); preparation (planning to initiate change in the next month); action (recently adopted a new behavior); and maintenance (continued the behavior for more than six months). Applied to coaches and the use of SP, this model suggests that prior to using SP services (e.g., adopting a new behavior) a coach will weigh the pros and cons and needs to understand how to integrate SP into their practice plans prior to making the decision. In early research using this model with athletes, Leffingwell, Rider, and Williams (2001) surveyed 308 NCAA Division I athletes and found that athletes in the action stage were most likely to initiate individual SP consultation. Keeler (2006) extended the TTM literature with 31 elite rugby athletes and found that $54.6 \%$ of athletes who initiated SP consultation were in action or maintenance and $45.5 \%$ were in contemplation. Additionally,

\footnotetext{
A publication from the National Association for Sport and Physical Education (NASPE), an association in the American Alliance for Health, Physical Education, Recreation and Dance (AAHPERD) 1900 Association Drive • Reston, Virginia • 20191 • www.NASPEinfo.org • 703.476.3410 (C)2008 by NASPE. All Rights Reserved.
} 


\section{Journal of Coaching Education}

almost half of the athletes were found to use all ten processes of change for mental skills training, with consciousness raising (e.g., gathering information about mental skills) most reported.

Because the TTM assumes that more subtle changes (e.g., changes in attitudes such as pros and cons) precede more obvious ones (e.g., regular use of SP services), researchers began to use the TTM to evaluate the effectiveness and impact of a SP workshop. Zizzi and Perna (2003) examined the initial impact of a 45-minute SP workshop that overviewed mental skills and addressed SP perceptions with 220 college and high school athletes on 14 teams. Results revealed that after the workshop athletes reported thinking about using services more and the perceived benefits increased, while perceived barriers decreased. Despite not having a control group, the changes observed are encouraging. For athletes in the early stages of change, Zizzi and Perna provided some support that addressing negative perceptions associated with SP can have an impact on athletes' readiness to use SP services. Instead of simply doing workshops about the content of SP (e.g., how to set effective goals), coach education workshops may be more effective by first, or concurrently, addressing perceptions of SP and helping coaches understand how to access and use the SP consultant most effectively.

Using the TTM as a framework, this study had two primary purposes. The first purpose was to examine the initial impact of an SP workshop on coaches' attitudes and readiness to use SP services. It was hypothesized that coaches' perceptions would be positively impacted by the workshop and that some coaches would move forward in their stage of readiness to use SP. The second purpose was to examine the impact of a stage-matched intervention on coaches' attitudes, readiness to use SP services, and actual behavioral SP usage patterns one month following the workshop. It was hypothesized that coaches in the intervention group would have a further increase in their intentions and actual use of SP services and a further decrease in perceived barriers at the one-month follow-up.

\section{Method}

\section{Participants}

Approximately 350 swimming coaches attended the Central States Swim Clinic (CSSC) and 103 participated in the workshop, representing a $29.68 \%$ response rate. However, due to incomplete or questionable data, 13 questionnaires were eliminated resulting in a sample of 90 coaches. Some coaches did not provide responses to demographic questions resulting in missing data. The sample included a fairly even distribution among gender (41 women, 44 men) and coaches who were in season $(n=48)$ and out of season $(n=41)$. The majority of the sample coached at the high school ( $n=38)$ and age-group $(n=23)$ level with the remaining 29 spread across the following levels: Division I, Division II, Division III, NAIA, club, masters, USS, and YMCA. The sample included 57 head coaches and 29 assistant coaches. On average, the sample had 9.65 ( $S D=7.88)$ years of coaching experience. The majority of coaches $(n=78)$ worked with both male and female swimmers. Nine (10\%) coaches reported access to SP services and two (2.2\%) Volume 1, Is 1,sue March 2008 Page 68

A publication from the National Association for Sport and Physical Education (NASPE), an association in the American Alliance for Health, Physical Education, Recreation and Dance (AAHPERD) 1900 Association Drive • Reston, Virginia • 20191 • www.NASPEinfo.org • 703.476.3410 (C)2008 by NASPE. All Rights Reserved. 


\section{Journal of Coaching Education}

of the coaches sampled had an SP consultant currently working with their team. Fourteen (15.6\%) coaches sampled had heard of AASP certification for SP.

\section{Instrumentation}

Attitudes. A shortened version of the Sport Psychology Attitudes Revised Coaches-2 (SPARC-2; Zakrajsek \& Zizzi, 2007) questionnaire was used to assess coaches’ attitudes. This scale contains 15 items assessing coaches' attitudes toward SP consulting on four subscales: stigma tolerance (five items); cultural preference (three); confidence in SP consultation (four); and personal openness (three). A six-point Likert-type scale, from one (strongly disagree) to six (strongly agree), was used. Interpretation and scores were obtained by averaging the responses within each subscale. Higher scores (closer to six) indicate a more negative attitude toward seeking SP consultation (stigma tolerance); a belief that SP consultation and mental training is useful (confidence in SP consultation); an unwillingness to be involved in SP consultation and mental training (personal openness); and a strong identification to nationality, ethnicity, culture, or race (cultural preference). Internal consistency reliability (Chronbach's alpha) estimates for the sample of swimming coaches were good to excellent: .90 (stigma tolerance), .87 (confidence in SP consultation), .82 (cultural preference), and .79 (personal openness).

Additional variables. Ten items were developed from pilot interviews with coaches and recent literature (Haslam, 2004; Pain \& Harwood, 2004; Voight \& Callaghan, 2001) to assess coaches' expectations and perceived barriers of using SP services. Perceived behavioral control was measured with one item modified from previous research with athletes (Anderson, Hodge, Lavallee, \& Martin, 2004) and included "If the coaching staff wanted to, we could easily access and use sport psychology services for the upcoming season.” One item was included to assess self-efficacy, which included "I would not know how to access a sport psychology professional for the upcoming season.” Four items were included for subjective norm, which assessed how important others would approve or disapprove of the desired behavior and if important others themselves perform the desired behavior (refer to Ajzen, 2002). Sample items included "the coaches whose opinions I respect use sport psychology services with their athletes" and "I feel pressure from people who are important to me to not access and use sport psychology services with our athletes.” The second item was modified from research with athletes (Anderson et al.). Response options for each item ranged from one (strongly disagree) to six (strongly agree). Scores for perceived barriers and subjective norms were obtained by averaging the responses.

Stage of change. Coaches' readiness to use SP services was assessed using a single-item ladder, which has been supported by previous literature (Grove, Norton, Van Raalte, \& Brewer, 1999). Coaches who reported not using SP services consistently two to four times per month were classified in one of the following stages of readiness: precontemplation (not thinking of using SP services); contemplation (thinking of using SP services); or preparation (use SP services but not regularly). Coaches who reported regular use of SP services were classified as follows: action (up to six months) or maintenance (more than 6 months). The number of coaches who were not Volume 1, Is 1,sue March $2008 \quad$ Page 69

A publication from the National Association for Sport and Physical Education (NASPE), an association in the American Alliance for Health, Physical Education, Recreation and Dance (AAHPERD) 1900 Association Drive • Reston, Virginia • 20191 • www.NASPEinfo.org • 703.476.3410 (C)2008 by NASPE. All Rights Reserved. 


\section{Journal of Coaching Education}

working with a SP consultant $(n=83)$ closely resembled the number of coaches in precontemplation and contemplation $(n=86)$, which provides some validation of the stage of change assessment measure.

Intentions and use of SP services. Four items were included to measure coaches' intentions to use SP services or refer athletes (Zakrajsek \& Zizzi, 2007). One item was also included to measure intentions to seek out more information about SP in the next month. Response options ranged from one (not at all likely) to six (very likely). Self-report items in the one-month followup survey included questions regarding contacting an SP consultant, contacting the researcher, using an SP consultant, gathering information, referring athletes, and accessing the website provided by the researcher. Web and email tracking was also used to assess coach behavior (e.g., how many times coaches accessed the website or emailed the consultant).

\section{Procedures}

Phase I. After institutional review board approval, permission was obtained from the clinic coordinator of the CSSC to have two one-hour sessions at the conference. After a brief explanation of the study and providing informed consent, coaches participated in a 30-minute workshop that focused on attitudes, expectations, barriers, and access to SP services. Prior to and following the workshop, coaches completed the survey packet, and at the end of the session, coaches were given a handout with the researcher's contact information and a website address that each coach had access to for the next month.

Phase II. Following the workshop, 45 coaches were randomly assigned to the stage-matched intervention group and the other 45 to the control group. One week following the workshop, the stage-matched group received a tailored manual via email as a pdf file attachment. Coaches in precontemplation received a manual titled "Why Mental Skills Training?” which focused on the benefits of SP services, anecdotal and empirical evidence of the value of SP consulting, and addressed misperceptions and concerns of the stigma associated with SP consulting. Coaches in contemplation received a manual titled "Give it a try" which discussed the benefits and barriers (e.g., time, money, and access) to using SP services. Coaches in preparation received a manual titled "Getting Started" which focused on making a commitment to mental skills training and discussed the process of SP consulting, the role of an SP consultant and coach, and how to initiate contact and set up a regular program. There were no coaches that identified being in the action or maintenance stage of change. The control group did not receive any additional materials.

Coaches in both the stage-matched and control groups received e-mail prompts once a week to access the website and contact the researcher with questions. The website contained information about SP services, news article links, and links to other resources, which changed each week to provide an incentive to consistently access the website. One month following the workshop, coaches were prompted to complete the follow-up survey online. The follow-up survey Volume
1 , Is 1 ,sue March 2008
Page 70

A publication from the National Association for Sport and Physical Education (NASPE), an association in the American Alliance for Health, Physical Education, Recreation and Dance (AAHPERD) 1900 Association Drive • Reston, Virginia • 20191 • www.NASPEinfo.org • 703.476.3410 (C)2008 by NASPE. All Rights Reserved. 


\section{Journal of Coaching Education}

contained the same information as the pre and post-workshop survey as well as questions regarding SP usage patterns. In addition to the follow-up survey, web and email tracking were used to assess coaching behaviors. In order to ensure confidentiality, the researcher was blind to coaches' contact information. A research assistant was responsible for emailing coaches the weekly reminders to check the website and email the appropriate stage-matched manual.

\section{Results}

Fifty-three swimming coaches completed all three data points (pre-workshop, post-workshop, and follow-up), representing a $41.1 \%$ attrition rate from post-workshop to the follow-up. Out of the 53 swimming coaches, 30 were in the stage-matched group and 23 were in the control group resulting in an attrition rate of 33.3\% and 56.6\% respectively. Two-way mixed ANOVAs were performed to test the study's hypotheses with one between group independent variable (grouptwo levels), one repeated measures independent variable (time- three levels), and nine dependent variables (stigma tolerance, confidence in SP consultation, cultural preference, personal openness, subjective norm, perceived behavioral control, self-efficacy, perceived barriers, and intentions). Therefore, the significance level was adjusted to .01 to control for Type I error. Adjusted F's (Greenhouse-Geisser) were reported for three variables (stigma tolerance, cultural preference, and subjective norm) because the assumptions of sphericity were violated.

Results of the two-way mixed ANOVAs revealed no significant interactions (group x time) on stigma tolerance $\left(F(1.6,96)=.11, p=.86, \eta^{2}=.002\right)$, confidence in SP consultation $(F(2,98)=$ $\left.1.11, p=.33, \eta^{2}=.022\right)$, personal openness $\left(F(2,98)=.96, p=.39, \eta^{2}=.019\right)$, and cultural preference $\left(F(1.7,98)=.35, p=.66, \eta^{2}=.007\right)$. However, a significant main effect for TIME was found for the dependent variable personal openness $\left(F(2,98)=7.04, p<.01, \eta^{2}=.126\right)$, revealing a moderate effect. Multiple comparisons revealed that coaches in both the stagematched and control groups became more open from pre to post-workshop $(p<.01)$ and less open from post-workshop to the follow-up $(p<.05)$. Refer to Table 1 for SPARC-2 subscale means over time.

The two-way mixed ANOVAs revealed no significant interactions (group x time) on subjective norm $\left(F(1.7,86)=2.87, p=.07, \eta^{2}=.063\right)$, perceived behavioral control $(F(2,98)=.81, p=$ $\left..45, \eta^{2}=.016\right)$, self-efficacy $\left(F(2,100)=.05, p=.97, \eta^{2}=.001\right)$, and perceived barriers $(F(2$, $\left.100)=.180, p=.84, \eta^{2}=.004\right)$. However, a significant main effect for TIME was found for the dependent variables perceived behavioral control, $\left(F(2,98)=10.5, p<.001, \eta^{2}=.176\right)$, selfefficacy $\left(F(2,100)=44.77, p<.001, \eta^{2}=.472\right)$, and perceived barriers $(F(2,100)=20.56, p<$ $\left..001, \eta^{2}=.291\right)$, revealing moderate to large effects. Multiple comparisons revealed that coaches perceived higher behavioral control from pre to post-workshop $(p<.001)$ and from preworkshop to the follow-up $(p<.05)$. With regard to self-efficacy, post-hoc testing revealed that both groups reported significantly higher self-efficacy from pre to post-workshop $(p<.001)$ and from pre-workshop to follow-up $(p<.001)$. Lastly, coaches' perceived barriers significantly 


\section{Journal of Coaching Education}

decreased from pre to post-workshop $(p<.001$ ) as well as from pre-workshop to the follow-up $(p<.001)$. It is worthwhile to note that, when looking at individual barrier items, money and time were consistently reported above the midpoint as barriers to service use across time.

The two-way mixed ANOVA revealed no significant interaction (group $\mathrm{x}$ time) on intentions $\left(F(2,92)=1.2, p=.31, \eta^{2}=.025\right)$. However, a significant main effect for TIME was found on the dependent variable intentions $\left(F(2,92)=15.58, p<.001, \eta^{2}=.253\right)$, with a large effect. Post-hoc testing revealed that coaches in both the stage-matched and control groups increased their intentions significantly from pre to post-workshop $(p<.001)$. Intentions returned close to baseline with a significant decrease from post-workshop to follow-up $(p<.001)$. Refer to Table 2 for means and standard deviations on the additional variables and intentions over time.

Stage of change. Prior to the workshop, 66 (73.3\%) swimming coaches identified themselves in precontemplation, $20(22.2 \%)$ in contemplation, and 4 (4.4\%) in preparation. Immediately following the workshop, $54(60.7 \%)$ coaches were in precontemplation, 32 (36\%) were in contemplation, and 3 (3.4\%) were in preparation. When looking further at the data, 12 (13.3\%) coaches had positive cognitive shifts from precontemplation to contemplation and one (1.1\%) coach had a negative cognitive shift, from preparation to precontemplation immediately following the workshop. On the 6-point manipulation check that ranged from one (very negative impact) to six (very positive impact), coaches reported that the workshop had a positive impact on their impression of SP services $(M=4.78, S D=1.05)$.

Of the 30 coaches who completed the follow-up in the stage-matched group, 19 (63.3\%) were in precontemplation, 10 (33.3\%) were in contemplation, and one (3.3\%) was in preparation at the one-month follow-up. When looking further at the data, three (10\%) coaches had positive cognitive shifts moving from precontemplation to contemplation, and five (16.6\%) coaches had negative cognitive shifts moving from contemplation to precontemplation. Of the 23 coaches who completed the follow-up in the control group, 13 (56.5\%) were in precontemplation and 10 (43.5\%) were in contemplation at the one-month follow-up. One (4.3\%) coach had a positive cognitive shift moving from precontemplation to contemplation.

Self-reported behaviors. The results of a two-way chi square analysis revealed no significant difference in the number of coaches who accessed the website between the stage-matched and control groups, $\chi^{2}(1, n=53)=.007, p=.933, \phi^{2}=.012$. Overall, 28 (52.8\%) coaches reported accessing the website: 16 (53.3\%) coaches from the stage-matched group and $12(52.2 \%)$ from the control group. Independent samples $t$-test revealed no significant difference, $t(25)=-.71, p=$ $.49, d=-.26$, in the mean number of times coaches in the stage-matched $(M=2.38, S D=1.45)$ and control group $(M=2.91, S D=2.47)$ accessed the website over four weeks.

\footnotetext{
A publication from the National Association for Sport and Physical Education (NASPE), an association in the American Alliance for Health, Physical Education, Recreation and Dance (AAHPERD) 1900 Association Drive • Reston, Virginia • 20191 • www.NASPEinfo.org • 703.476.3410 (C)2008 by NASPE. All Rights Reserved.
} 


\section{Journal of Coaching Education}

The results of a two-way chi square analysis revealed no significant difference in the number of coaches that sought out more information about SP between the stage-matched and control groups, $\chi^{2}(1, n=53)=.058, p=.81, \phi^{2}=.033$. Ten (18.9\%) coaches reported seeking out more information about SP: six (20.0\%) coaches in the stage-matched group and four (17.4\%) coaches in the control group. Frequencies are reported for each behavior in Table 3, including those that could not be analyzed via chi-square due to low cell counts.

Website and email tracking. Overall, 69 website hits were recorded over four weeks, in which 38 (55.07\%) of the hits were from participants in the stage-matched group and 31 (44.93\%) of the website hits were from participants in the control group. Overall 38 (40\%) individual coaches who participated in the workshop accessed the website. A total of 19 individual coaches in the stage-matched group and 19 individual coaches in the control group accessed the website. On a Likert-type scale from one (not at all) to six (very), coaches rated the helpfulness of the website near the midpoint $(M=3.40, S D=1.20)$. A total of one coach, in the control group, emailed the researcher with a question regarding SP services over the four-week time period. Refer to Table 3 for website and email tracking over the four-week time period.

\section{Discussion}

The current study provided some evidence of the impact of a tailored workshop on coaches' readiness to use SP services, in which $13.3 \%$ of swim coaches' shifted from precontemplation to contemplation. It appears that the effect the current workshop had on increasing coaches perceived behavioral control, self-efficacy, personal openness, and intentions, while decreasing perceived barriers may have shifted some from not thinking about using services (precontemplation) to thinking about using SP services for the upcoming season (contemplation). This percentage is relatively close to previous literature in which, $16 \%$ of athletes experienced positive cognitive shifts after an SP workshop (Zizzi \& Perna, 2003). This result suggests that a brief one-time SP workshop can expect to impact roughly $13 \%$ to $16 \%$ of the sample's readiness in a positive direction. This is consistent within the TTM, as it would be unrealistic to expect a coach to jump into action after a brief workshop; therefore, it makes sense to see more subtle changes with the greatest impact on shifting coaches from precontemplation to contemplation.

Although the workshop had a positive impact on coaches' readiness to use SP services, this impact was not sustained over time or further impacted by the stage-appropriate follow-up intervention. This finding is contradictory to the idea of maximizing impact with tailored selfhelp interventions, in which previous literature has found stage-appropriate manuals to be successful in facilitating forward movement in readiness for physical activity behaviors (Marcus et al. 1998). Furthermore, the majority of coaches were in precontemplation and contemplation and previous literature has found stage-matched self-help interventions to be particularly useful for individuals in the earlier stages of change (Marcus et al.). Similarly, swim coaches' intentions were impacted positively by the workshop; however, they remained relatively low and regressed to the pre-workshop mean at the follow-up. Again, this is contradictory to maximizing impact $\begin{array}{lll}\text { Volume 1, Is 1,sue March } 2008 & \text { Page } 73\end{array}$

A publication from the National Association for Sport and Physical Education (NASPE), an association in the American Alliance for Health, Physical Education, Recreation and Dance (AAHPERD) 1900 Association Drive • Reston, Virginia • 20191 • www.NASPEinfo.org • 703.476.3410 (C)2008 by NASPE. All Rights Reserved. 


\section{Journal of Coaching Education}

with stage-appropriate interventions and suggests that if intentions are not acted on quickly they will mostly likely regress.

Previous literature has primarily focused on attitudes and addressing confidence and stigma tolerance with coaches and athletes in order to help increase service use (Anderson et al. 2004; Leffingwell et al. 2001; Zakrajsek \& Zizzi, 2007). Interestingly, the current sample of swimming coaches entered the workshop with low stigma tolerance scores and high scores on confidence; therefore, a ceiling effect may have limited the amount of impact the workshop or follow-up intervention could have on these variables. Swim coaches were somewhat open to using SP services prior to the workshop but openness may have had more room for improvement in comparison to the other SPARC-2 variables. Although swim coaches became more willing to use SP services, the effect should not be over-interpreted since the gains were not maintained at the one-month follow-up. Thus, the intended impact of the workshop or tailored manuals may not have occurred for most coaches.

It is interesting that coaches' attitudes were so positive prior to entering the workshop given that only three coaches had previous experience with SP consultation. This is inconsistent with previous literature in which athletes who previously used SP services at least once were found to have higher confidence and lower stigma toward SP consultation compared to athletes without previous experience (Anderson et al. 2004; Martin, 2005). It is possible that perceptions and attitudes toward SP have become more favorable as the field has grown in visibility since the 1980’s. In addition, Martin, Lavallee, Kellman, and Page (2004) found that types of sport may influence attitudes toward SP consultation. For instance, athletes in physical non-contact sports, such as swimming, held a more positive view of SP consulting compared to athletes in physical contact sports. Because coaches hold a different role regarding SP service use, caution must be noted when translating athletes' attitudes to coaches' attitudes and the use of SP services. Research regarding athletes' attitudes is more developed compared to research with coaches. Therefore, in order to fully understand how coaches' previous experience and type of sport impact attitudes, more research with coaches is needed. Nonetheless, the overall positive attitude toward SP consulting is encouraging and suggests that swim coaches' may be interested, receptive, and confident in using SP services.

The positive attitudes and interest in SP would suggest that many of these coaches would become consumers of SP services if they had access and the services were free or affordable. Interestingly, the sample of swimming coaches had positive attitudes toward SP consultation yet the vast majority was in the early stages of readiness, had relatively low intentions, and had low behavioral usage patterns. This is interesting since seeking out more information, utilizing a free website and SP resource (e.g., the researcher), and talking to others to inquire about SP services would be some of the expected behaviors of someone with positive attitudes and thinking about using SP services for the upcoming season.

Volume 1, Issue 1, March 2008

Page 74

A publication from the National Association for Sport and Physical Education (NASPE), an association in the American Alliance for Health, Physical Education, Recreation and Dance (AAHPERD) 1900 Association Drive • Reston, Virginia • 20191 • www.NASPEinfo.org • 703.476.3410 (C)2008 by NASPE. All Rights Reserved. 


\section{Journal of Coaching Education}

The mismatch between attitudes and readiness does not support the usefulness of the TTM in this population and for this specific behavior (using SP services). For instance, coaches in the early stages of motivational readiness would be expected to have less favorable attitudes toward SP service use. Although more research is needed with regard to the TTM and coaches' use of SP services, it may be beneficial to explore the appropriateness of other theories. According to the theory of planned behavior (Ajzen, 2002), an individual's perception of behavioral control influences the decision to carry out an intended behavior. Although swim coaches learned more about how to access an SP professional (self-efficacy), coaches did not report high behavioral control. This suggests that swim coaches in the early stages of readiness may continue to be inhibited if they do not believe they have volitional control or can easily access and use SP services.

The majority of the sample coached at the high school or age-group level and; therefore, may have limited access to SP services compared to higher levels of competition (e.g., collegiate and professional). Overall, $10 \%$ of swimming coaches in the current sample reported having access to SP services. In addition, when looking at individual items addressing swim coaches' barriers to service use, money and time continued to be reported as the highest. High school or age-group coaches are likely to have a very restricted budget compared to their college or pro counterparts, making it more difficult to contract the services of an SP professional. For coaches in the early stages of readiness, the perceived degree of difficulty in executing the behavior (due to time, money, and access) may outweigh the effort that coaches are willing to put forth in creating opportunity and resources for SP service use regardless of having positive attitudes.

Within the theory of planned behavior, Ajzen (2007) suggests that interventions need to be designed toward factors that have more room for change. Thus, if attitudes are already positive then one would not expect an intervention designed to make attitudes more favorable to influence behavior. Therefore, other variables with more room for change (e.g., controllability and barriers) would more likely have a greater impact on intentions and behavioral usage patterns. It appears that the workshop was not effective in clearly addressing controllability and ease in accessing SP services and; therefore, the effect of the workshop was not strong enough to overcome the combined barriers to increase service use. This does not imply that attitudes are not important to service use. The fact that coaches consistently report the importance of mental skills and a willingness to use SP services may be partially due to the positive attitudes toward SP. However, the current findings suggest that SP professionals may benefit from spending more time on the issue of perceived controllability and helping coaches understand why they should prioritize SP services.

Interestingly, the manuals tailored toward contemplation focused on decreasing the barriers commonly mentioned by coaches (e.g., time, money, access), which seems to have been a near exact match for the profile of many coaches in this sample. However, only 13 (48\%) swim coaches in the stage-matched group reported actually reading the manual. It is clear that over half Volume 1, Is 1,sue March 2008

Page 75

A publication from the National Association for Sport and Physical Education (NASPE), an association in the American Alliance for Health, Physical Education, Recreation and Dance (AAHPERD) 1900 Association Drive • Reston, Virginia • 20191 • www.NASPEinfo.org • 703.476.3410 (C)2008 by NASPE. All Rights Reserved. 


\section{Journal of Coaching Education}

of the swim coaches did not receive the intended intervention. Four of the eight swim coaches that responded to an open-ended question said they had not read the manual due to a lack of time. One coach responded, "I have not had a chance to really look at the information, I'm sorry this has been a really busy month.” From this statement and the fact that $52 \%$ of swimming coaches did not read the manual, it is clear the coaches did not make SP service use a priority and that no need was established after the workshop.

\section{Limitations}

A few additional limitations warrant discussion. First, results of the current sample may not generalize to other coaches, sports, or levels of competition as well as other swim coaches not present at the workshop or conference. It would be worthwhile to study the impact of interventions with coaches at higher levels of competition that may have more access to SP professionals. Second, the current study did not have a true control group. Although the control group did not receive the stage-matched intervention, they did receive the SP workshop and had access to the website. Future research should consider comparing coaches’ perceptions, readiness, and use of SP services between those who received an intervention and those that received no intervention at all. Third, the current study utilized coaching conferences to conduct the workshop. Although this is useful, coaches are away from their busy schedules and day to day activities. Once back in their environment, SP may not be prioritized since it may be viewed as a "luxury" component to training and is often not viewed as a traditional aspect of sport. Lastly, the one-month follow-up may not have been enough time for coaches to change their behavior or stage of change profiles. Considering that the vast majority of coaches were in precontemplation or contemplation, one month would not have been enough time to expect coaches to shift into preparation or action.

Applied Implications

From the current study, it is clear that establishing a need and prioritizing SP services is important during a workshop and intervention with coaches. Therefore, it would be beneficial for a practitioner to understand and tailor a workshop within the context of their audience (e.g., level of sport, type of sport, time of season, previous experience with SP, and if the coach works part time or full time). For instance, the performance gains related to physical training and technique may be viewed as high and immediate at the high school and age-group level. Therefore, coaches may need to understand the immediate value or need of SP to their level of athletes. In addition, coaches need to believe they have the resources and opportunities to use SP services. Money was viewed as the number one barrier to service use with the current sample and has been repeatedly reported as a barrier throughout the SP literature. Especially with high school and youth programs, there may be other important sources (e.g., parents, boosters) willing to donate funding for mental skills training. Sport psychology professionals can educate coaches with restricted budgets regarding other possible sources for funding, offer services for free initially, or provide a variety of packages at different price points. 


\section{Journal of Coaching Education}

As noted previously, coaches perceived having little control over the ease in accessing and using services. One suggestion to facilitate the ease for coaches to carry out intentions is to form an implementation intention (Gollwitzer, 1999) which focuses on formulating specific plans that identify when, where, and how the intended behavior will be carried out. Therefore, coaches that intend to seek out more information or use services can identify how and when they will access information or contact an SP professional. Planning may be a key skill to transfer learning from an applied SP workshop which may increase commitment and strengthen the link between intentions and behavior rather than regress and weaken the intention-behavior link. For coaches in the early stages of readiness, it may be more appropriate to formulate plans to carry out simple behaviors. For instance, approximately $40 \%$ of the coaches who attended the SP workshop accessed the website during the four-week follow-up. Given that most coaches were in the early stages of readiness, accessing a website may be the simplest behavior and least invasive approach for coaches to gather SP information.

AASP, the largest organization of its kind in North America, has developed the Coaching Science- Special Interest Group (CS-SIG) to promote SP in coaching. Mental skills and SP may have increased in visibility; however, only $15.6 \%$ of swimming coaches had heard of AASP certification. During the annual AASP conference in 2007, members of the organization provided, for a small fee, an applied SP workshop for coaches within the local area. This is an encouraging step taken by AASP members and hands-on applied workshops need to continue to be marketed and offered to area coaches. Perhaps the CS-SIG and AASP would also be interested in partnering with coaching organizations to provide their member coaches access to applied SP techniques and strategies through a series of workshops. These approaches may be a useful foundation to build rapport and credibility, increase accessibility to competent SP professionals who are AASP certified, and work around the barriers of time and money that are so commonly cited by coaches. In addition, continued efforts to expose and train coaches in applied SP (e.g., through coaches' clinics and academic courses) may lead to greater SP literacy, a sense of control, and perhaps higher intentions to use SP.

As the first attempt at developing stage-appropriate interventions with coaches, further research is needed with regard to the appropriateness of self-help interventions as a strategy to impact coaches' readiness and intentions to use SP services. Coaches' low readiness most likely is impacted by perceived controllability in the ease of accessing services as well as barriers such as time and money. Therefore, future research needs to examine if the theory of planned behavior may be a more appropriate framework to use when understanding SP service use and developing interventions with coaches. 


\section{Journal of Coaching Education}

\section{References}

Ajzen, I. (2002). Constructing a TPB questionnaire: Conceptual and methodological considerations. Retrieved October 3, 2006, from http://wwwunix.oit.umass.edu/ ajzen/tpb.html

Ajzen, I. (2007). Behavioral interventions based on the theory of planned behavior. Retrieved November 3, 2007 from http://www.people.umass.edu/aizen/pdf/tpb.intervention.pdf

Anderson, A. G., Hodge, K. P., Lavallee, D., \& Martin, S. (2004). New Zealand athletes’ attitudes towards seeking sport psychology consultation. New Zealand Journal of Psychology, 33, 129-136.

Cale, A., \& Crisfield, P. (1994). Advances in British coach education: A sports psychology perspective. In F. I. Bell \& G. H. Van Gyn (Eds.), Proceedings for the $10^{\text {th }}$ Commonwealth \& International Scientific Congress: access to active living, University of Victoria, 560-564.

Cassidy, T., Potrac, P., \& McKenzie, A. (2006). Evaluating and reflecting upon a coach education initiative: The CoDe of rugby. The Sport Psychologist, 20, 145-161.

Gollwitzer, P. M. (1999). Implementation intentions: Strong effects of simple plans. American Psychologist, 54, 493-503.

Gould, D., Medberry, R., Damarjian, N., \& Lauer, L. (1999). A survey of mental skills training knowledge, opinion, and practices of junior tennis coaches. Journal of Applied Sport Psychology, 11, 28-50.

Grove, J. R., Norton, P. J., Van Raalte, J. L., \& Brewer, B. W. (1999). Stage of change as an outcome measure in the evaluation of mental skills training programs. The Sport Psychologist, 13, 107-116.

Haslam, I. R. (2004). Psychological skills training: A qualitative study of Singapore coaches. Journal of Physical Education \& Recreation, 10, 37-47.

Keeler, L. A. (2006). The transtheoretical model and psychological skills training: Application and implications with elite female athletes. Unpublished doctoral dissertation, West Virginia University, Morgantown. 


\section{Journal of Coaching Education}

Kremer, P. J., \& Marchant, D. B. (2002). Reflections and considerations of providing sport psychology services with professional football players. In W. Spinks (Ed.), Science and Football IV (pp.294-299). London: Routledge.

Leffingwell, T. R., Rider, S. P., \& Williams, J. M. (2001). Applications of the Transtheoretical model to psychological skills training. The Sport Psychologist, 15, 168-187.

Marcus, B. H., Emmons, K. M., Simikin-Silverman, L. R., Linnan, L. A., Taylor, E. R., Bock, B. C., et al. (1998). Evaluation of motivationally tailored vs. standard self-help physical activity interventions at the workplace. American Journal of Health Promotion, 12, 246253.

Martin, S. B. (2005). High school and college athletes’ attitudes toward sport psychology consulting. Journal of Applied Sport Psychology, 17, 127-139.

Martin, S. B., Akers, A., Jackson, A. W., Wrisberg, C. A., Nelson, L., Leslie, P. J., et al. (2001). Male and female athletes' and nonathletes' expectations about sport psychology consulting. Journal of Applied Sport Psychology, 13(1), 18-39.

Martin, S. B., Lavallee, D., Kellman, M., \& Page, S. J. (2004). Attitudes toward sport psychology consulting of adult athletes from the United States, United Kingdom, and Germany. International Journal of Sport and Exercise Psychology, 2, 146-160.

National Association for Sport and Physical Education. (2006). Quality coaches, quality sports: National standards for sport coaches ( $2^{\text {nd }}$ ed.). Reston, VA: Author.

Pain, M. A., \& Harwood, C. G. (2004). Knowledge and perceptions of sport psychology within English soccer. Journal of Sports Sciences, 22, 813-826.

Prochaska, J. O., \& DiClemente, C. C. (1983). Stages and processes of self-change of smoking: toward an integrative model of change. Journal of Consulting and Clinical Psychology, 51, 390-395.

Scully, D., \& Hume. A. (1995). Sport psychology: Status, knowledge and use among elite level coaches and performers in Ireland. The Irish Journal of Psychology, 16, 52-66.

Speed, H. D., Andersen, M. B., \& Simons, J. (2005). The selling or the telling of sport psychology; presenting services to coaches. In M. B. Andersen (Ed.), Sport psychology in practice (pp. 1-16). Champaign, IL: Human Kinetics. 


\section{Journal of Coaching Education}

Voight, M., \& Callaghan, J. (2001). The use of sport psychology services at NCAA Division I Universities. The Sport Psychologist, 15, 91-102.

Zakrajsek, R. A., \& Zizzi, S. J. (2007). Factors influencing track and swimming coaches' intentions to use sport psychology services. Athletic Insight: The Online Journal of Sport Psychology, 9(2). Retrieved September 29, 2007, from http://www.athleticinsight.com/Vol9Iss2/CoachesIntentions.htm

Zizzi, S. J., \& Perna, F. M. (2003). Impact of a brief workshop on stages of change profiles in athletes. Athletic Insight: The Online Journal of Sport Psychology, 5(4). Retrieved October, 24, 2004, from

http://www.athleticinsight.com/Vol5Iss4/ImpactofBriefWorkshop.htm 


\section{Journal of Coaching Education}

Table 1: Swimming Coaches Scores on SPARC-2 Subscales Over Time.

\begin{tabular}{|c|c|c|c|c|c|c|c|}
\hline & & \multicolumn{2}{|c|}{ Pre-Workshop } & \multicolumn{2}{|c|}{ Post-Workshop } & \multicolumn{2}{|c|}{ Follow-Up } \\
\hline & & MEAN & $\underline{\mathrm{SD}}$ & MEAN & $\underline{\mathrm{SD}}$ & MEAN & $\underline{\mathrm{SD}}$ \\
\hline & Stage-Matched & 1.65 & .68 & 1.59 & .72 & 1.58 & .77 \\
\hline \multirow[t]{3}{*}{ Stigma Tolerance } & Control & 1.60 & .69 & 1.56 & .72 & 1.60 & .65 \\
\hline & Total Sample & 1.62 & .68 & 1.58 & .71 & 1.59 & .71 \\
\hline & Stage-Matched & 5.12 & .85 & 5.15 & .76 & 4.87 & .81 \\
\hline \multirow{3}{*}{$\begin{array}{l}\text { Confidence in SP } \\
\text { Consultation }\end{array}$} & Control & 4.93 & .87 & 5.06 & .98 & 4.95 & .98 \\
\hline & Total Sample & 5.04 & .85 & 5.11 & .84 & 4.90 & .88 \\
\hline & Stage-Matched & 2.82 & 1.13 & 2.66 & 1.15 & 3.01 & 1.11 \\
\hline \multirow[t]{3}{*}{$\begin{array}{l}\text { Cultural } \\
\text { Preference }\end{array}$} & Control & 2.77 & 1.14 & 2.77 & 1.29 & 3.21 & 1.02 \\
\hline & Total Sample & 2.80 & 1.13 & 2.71 & 1.20 & 3.10 & 1.07 \\
\hline & Stage-Matched & 2.83 & 1.02 & 2.31 & 1.05 & 2.71 & 1.01 \\
\hline \multirow[t]{2}{*}{$\begin{array}{l}\text { Personal } \\
\text { Openness }\end{array}$} & Control & 3.02 & .90 & 2.79 & 1.06 & 3.00 & .95 \\
\hline & Total Sample & 2.91 & .97 & 2.51 & 1.07 & 2.83 & .99 \\
\hline
\end{tabular}

Note. Scores closer to six indicate higher stigma, confidence in SP consultation, lower personal openness, and a strong cultural preference.

A publication from the National Association for Sport and Physical Education (NASPE), an association in the American Alliance for Health, Physical Education, Recreation and Dance (AAHPERD) 1900 Association Drive • Reston, Virginia • 20191 • www.NASPEinfo.org • 703.476.3410 (C)2008 by NASPE. All Rights Reserved. 


\section{Journal of Coaching Education}

Table 2: Swimming Coaches Scores on Dependent Variables Over Time.

\begin{tabular}{|c|c|c|c|c|c|c|c|}
\hline & & \multicolumn{2}{|c|}{ Pre-Workshop } & \multicolumn{2}{|c|}{ Post-Workshop } & \multicolumn{2}{|c|}{ Follow-Up } \\
\hline & & MEAN & $\underline{\mathrm{SD}}$ & MEAN & $\underline{\mathrm{SD}}$ & MEAN & $\underline{\mathrm{SD}}$ \\
\hline & Stage-Matched & 3.80 & .790 & 4.02 & .86 & 4.01 & .75 \\
\hline \multirow[t]{3}{*}{ Subjective Norm } & Control & 4.15 & .86 & 4.45 & .84 & 4.00 & .80 \\
\hline & Total Sample & 3.96 & .83 & 4.22 & .87 & 4.01 & .77 \\
\hline & Stage-Matched & 2.46 & 1.17 & 3.14 & 1.32 & 2.89 & .96 \\
\hline \multirow{3}{*}{$\begin{array}{l}\text { Perceived } \\
\text { Behavioral } \\
\text { Control }\end{array}$} & Control & 1.87 & 1.25 & 3.04 & 1.49 & 2.70 & 1.58 \\
\hline & Total Sample & 2.20 & 1.23 & 3.10 & 1.39 & 2.80 & 1.27 \\
\hline & Stage-Matched & 4.41 & 1.32 & 2.62 & 1.05 & 2.62 & 1.08 \\
\hline \multirow[t]{3}{*}{ Self-Efficacy } & Control & 4.04 & 1.89 & 2.17 & 1.27 & 2.30 & 1.15 \\
\hline & Total Sample & 4.25 & 1.6 & 2.42 & 1.16 & 2.48 & 1.11 \\
\hline & Stage-Matched & 3.10 & .84 & 2.67 & .71 & 2.66 & .81 \\
\hline \multirow[t]{3}{*}{$\begin{array}{l}\text { Perceived } \\
\text { Barriers }\end{array}$} & Control & 3.05 & .98 & 2.51 & .73 & 2.53 & .67 \\
\hline & Total Sample & 3.08 & .90 & 2.60 & .71 & 2.60 & .75 \\
\hline & Stage-Matched & 2.53 & 1.14 & 3.07 & 1.06 & 2.57 & .89 \\
\hline \multirow[t]{2}{*}{ Intentions } & Control & 2.41 & 1.10 & 3.38 & 1.44 & 2.75 & 1.23 \\
\hline & Total Sample & 2.48 & 1.10 & 3.2 & 1.23 & 2.65 & 1.04 \\
\hline
\end{tabular}

Note. Scores closer to six indicate a stronger norm for using SP services, higher perceived behavioral control, lower self-efficacy, higher perceived barriers, and higher intentions to use SP services.

Volume 1, Issue 1, March 2008

Page 82

A publication from the National Association for Sport and Physical Education (NASPE), an association in the American Alliance for Health, Physical Education, Recreation and Dance (AAHPERD) 1900 Association Drive • Reston, Virginia • 20191 • www.NASPEinfo.org • 703.476.3410 (C)2008 by NASPE. All Rights Reserved. 
Table 3: Swimming Coaches Behavioral Usage Patterns

\begin{tabular}{|c|c|c|c|c|c|c|}
\hline & \multicolumn{2}{|c|}{$\begin{array}{l}\text { Stage-Matched } \\
\qquad(n=30)\end{array}$} & \multicolumn{2}{|c|}{$\begin{array}{l}\text { Control } \\
(n=23)\end{array}$} & \multicolumn{2}{|c|}{$\begin{array}{c}\text { Total } \\
(N=53)\end{array}$} \\
\hline & Frequency & $\begin{array}{l}\text { Valid } \\
\text { Percent }\end{array}$ & Frequency & $\begin{array}{l}\text { Valid } \\
\text { Percent }\end{array}$ & Frequency & $\begin{array}{l}\text { Valid } \\
\text { Percent }\end{array}$ \\
\hline Accessed the Website & 19 & 63.33 & 19 & 82.61 & 38 & 71.70 \\
\hline $\begin{array}{l}\text { Sought out More Information } \\
\text { About SP }\end{array}$ & 6 & 20.0 & 4 & 17.39 & 10 & 18.87 \\
\hline Contacted an SPC & 0 & 0.0 & 1 & 4.35 & 1 & 1.89 \\
\hline Referred an Athlete & 1 & 3.33 & 1 & 4.35 & 2 & 3.77 \\
\hline $\begin{array}{l}\text { Contacted the Researcher via } \\
\text { Email }\end{array}$ & 1 & 3.33 & 1 & 4.35 & 2 & 3.77 \\
\hline
\end{tabular}

Direct Correspondence to: Rebecca A. Zakrajsek

Indiana State University, Arena C-24

Terre Haute, Indiana 47809

Tel: 812.237.3906

Fax: 812.237.4338

email: rzakrajsek@isugw.indstate.edu

Second Author Contact Information:

Sam J. Zizzi

West Virginia University

PO Box 6116, WVU School of PE

Morgantown, WV 26506-6116

Tel: 304.293.3295 ext 5240

email: szizzi@mail.wvu.edu

Volume 1, Issue 1, March 2008

Page 83

A publication from the National Association for Sport and Physical Education (NASPE), an association in the American Alliance for Health, Physical Education, Recreation and Dance (AAHPERD) 1900 Association Drive • Reston, Virginia • 20191 • www.NASPEinfo.org • 703.476.3410 (C)2008 by NASPE. All Rights Reserved. 